\title{
Mecanismos de defesa eliciados por ulvana contra Uromyces appendiculatus em três cultivares de feijoeiro
}

\author{
Leandro C. Borsatoํㅜ, Robson M. Di Piero² \& Marciel J. Stadnik ${ }^{2}$ \\ ${ }^{1}$ Instituto Agronômico do Paraná - IAPAR, 86001 970, Londrina, PR, Brasil; ${ }^{2}$ Departamento de Fitotecnia, Centro de \\ Ciências Agrárias, Universidade Federal de Santa Catarina, 88040 900, Florianópolis, SC, Brasil
}

Autor para correspondência: Marciel J. Stadnik, e-mail: stadnik@cca.ufsc.br

\begin{abstract}
RESUMO
O objetivo deste trabalho foi avaliar o potencial do polissacarídeo ulvana em induzir resistência à ferrugem e estudar os mecanismos de defesa desencadeados em cultivares de feijoeiro apresentando diferentes níveis de resistência. Para tanto, plantas de feijoeiro do grupo carioca, BR IPA - 11 Brígida (resistente), Pérola (moderadamente suscetível) e IPR Juriti (suscetível), foram pulverizadas com ulvana (10 $\mathrm{mg} / \mathrm{mL}$ ) ou água destilada (testemunha) aos 6 e 3 dias antes da inoculação com Uromyces appendiculatus. Ulvana reduziu o diâmetro das pústulas nas três cultivares e provocou o aumento na atividade de glucanases apenas na cv. Pérola, $48 \mathrm{~h}$ após a inoculação. O polissacarídeo não inibiu a germinação do fungo em discos foliares e não alterou a atividade de peroxidases. Comparando-se as cultivares, Brígida exibiu significativamente um menor número e diâmetro de pústulas, mas possibilitou a maior germinação de uredósporos na superfície foliar. As atividades de peroxidases e glucanases foram menores nessa cultivar em relação à suscetível (Juriti). Com base nos resultados, discute-se o papel de alguns mecanismos nas resistências basal e induzida por ulvana em feijoeiro em relação ao agente causal da ferrugem.
\end{abstract}

Palavras-chave: Ferrugem, germinação, indução de resistência, proteínas-RP.

\section{ABSTRACT}

Mechanisms of defense elicited by ulvan against Uromyces appendiculatus in three bean cultivars

The aim of this work was to evaluate the potential of algal polysaccharide ulvan to induce resistance to rust and to study defense mechanisms triggered by it in bean cultivars showing different levels of resistance. Bean cultivars of carioca group, i.e., BR IPA 11 Brigida (resistant), Perola (moderately susceptible) and IPR Juriti (susceptible), were sprayed with ulvan $(10 \mathrm{mg} / \mathrm{mL})$ or distilled water (control) at 6 and 3 days before inoculation with Uromyces appendiculatus. Ulvan reduced the diameter of pustules on the three cultivars and led to an increase in the activity of glucanases only in cv. Perola, $48 \mathrm{~h}$ after inoculation. The polysaccharide did not inhibit the germination of the fungus in leaf discs and did not alter the activity of peroxidases. Comparing the cultivars, Brigida exhibited a significantly lower number and diameter of pustules, but allowed the highest germination of uredospores on the leaf surface. The activities of peroxidases and glucanases were lower in this cultivar compared to the susceptible one (Juriti). Based on the results, we discuss the role of some resistance mechanisms in both basal and ulvan-induced resistance of bean towards the rust fungus.

Key words: bean rust, germination, resistance induction, PR-proteins.

O feijão é considerado um alimento de grande importância econômica e social, constituindo uma das principais fontes de proteína utilizadas na alimentação da população brasileira. Dentre o grande número de doenças que ocorrem na cultura, a ferrugem causada pelo fungo Uromyces appendiculatus F. Strauss é considerada uma das mais importantes, podendo causar prejuízos de até $45 \%$ na produção em cultivares suscetíveis, sob ambiente favorável (Jesus Junior et al., 2001).

Os primeiros sintomas são observados na superfície abaxial das folhas, 6 a 7 dias após a infecção, como pequenas manchas esbranquiçadas "flecks" levemente salientes, recobertas pela cutícula da folha, que vão aumentando de

Parte da Dissertação de Mestrado do primeiro autor. Universidade Federal de Santa Catarina. Florianópolis SC. 2009. tamanho, até que aos 10 a 12 dias rompem a epiderme formando pústulas maduras marrom-avermelhadas, que caracterizam o sintoma típico. As temperaturas mais adequadas para a germinação dos uredósporos estão entre 12,5 e $22^{\circ} \mathrm{C}$ (Mcmillan et al., 2003).

Apesar de existência de cultivares resistentes à ferrugem, o controle genético desta doença é dificultado devido à presença de inúmeras raças fisiológicas do patógeno (Singh, 2001). Devido aos problemas ambientais causados pelo uso de agrotóxicos e aos freqüentes relatos do aparecimento de isolados de $U$. appendiculatus resistentes aos fungicidas, a agricultura moderna exige o desenvolvimento de medidas alternativas ao controle químico. A indução de resistência pode ser entendida como o aumento da atividade dos mecanismos estruturais e/ou bioquímicos de respostas de defesa da planta pela utilização de agentes externos, de origem biótica ou abiótica. Os 
mecanismos ativados podem envolver a formação de papilas, halos, tiloses, além da síntese de compostos como fitoalexinas e proteínas relacionadas à patogênese, tais como peroxidases e glucanases (Kiraly et al., 2007).

Os polissacarídeos obtidos de algas marinhas têm demonstrado efeito como potenciais indutores de respostas de defesa das plantas (Aziz et al., 2003; Cluzet et al., 2004; Paulert et al., 2009). Entre esses, destaca-se a ulvana, presente na parede celular de algas do gênero Ulva spp., as quais são encontradas em todo o litoral brasileiro (Paulert et al., 2009). Nesse sentido, os objetivos do atual trabalho são avaliar a capacidade da ulvana em induzir resistência em três cultivares de feijoeiro contra o agente causal da ferrugem e estudar os mecanismos de ação envolvidos.

As amostras da alga Ulva fasciata foram coletadas manualmente em janeiro de 2007 nos costões rochosos da praia da Armação (latitude: $27^{\circ} 44^{\prime} 53,7^{\prime}$ S; longitude: $48^{\circ}$ 29' 55,6”, Florianópolis, Santa Catarina), lavadas em água corrente e secas em estufa a $50^{\circ} \mathrm{C}$ durante $48 \mathrm{~h}$. A extração do polissacarídeo foi baseada em Fernandes (2007).

Plantas de feijão carioca BR IPA - 11 Brígida (resistente), IPR Juriti (suscetível) e Pérola (padrão moderadamente suscetível) foram cultivadas no período de setembro a outubro de 2007 em casa-de-vegetação, com temperaturas médias variando de 19 a $23^{\circ} \mathrm{C}$, em vasos contendo $2 \mathrm{~kg}$ de mistura homogênea (v/v) de solo argiloso $(75 \%)$ e composto orgânico (25\%). As plantas, no estádio $\mathrm{V} 3$, foram tratadas com água destilada ou ulvana $(10 \mathrm{mg} /$ $\mathrm{mL})$ e, 3 e 6 dias depois, inoculadas com uma suspensão de $10^{6}$ uredósporos $/ \mathrm{mL}$ de $U$. appendiculatus (isolado MANE4). Após a aspersão de um volume de $2 \mathrm{~mL} /$ planta, os vasos foram acondicionados em câmara úmida por 48 horas. Findo este período, as plantas retornaram para as bancadas da casa-de-vegetação, onde permaneceram até a avaliação do experimento. A determinação do número de pústulas $/ \mathrm{cm}^{2}$ e do diâmetro das pústulas foram efetuados aos 15 dias após a inoculação, no primeiro trifólio de cada planta.

Para as análises microscópicas, foram coletados três discos foliares de $9 \mathrm{~mm}$ de diâmetro obtidos a partir do folíolo central do primeiro trifólio de cada cultivar, tratados com ulvana ou água destilada, 48 horas após a inoculação. Os discos foliares coletados foram imediatamente colocados com a superfície abaxial voltada para cima, em placas de Petri contendo papel de filtro umedecido com solução de etanol e ácido acético $(3: 1 \mathrm{v} / \mathrm{v})$ para a retirada da clorofila. A solução foi trocada periodicamente durante 3 dias. Em seguida, os discos foram lavados com água destilada e fixados em solução de lactoglicerol, ácido lático e água destilada $(1: 1: 1 \mathrm{v} / \mathrm{v})$ (Stadnik \& Buchenauer, 2000) e examinados com o auxílio de um microscópio óptico, sob aumento de 480X (PZO, modelo StudarLab, Polônia). A porcentagem de germinação e a formação de apressórios sobre os estômatos foram determinadas em cerca de 40 uredósporos por repetição.

Para as análises da atividade das enzimas peroxidases e glucanases, foram coletados, respectivamente, o folíolo lateral esquerdo e direito do primeiro trifólio de plantas tratadas com ulvana e das testemunhas, 48 horas após a inoculação. As amostras foram maceradas em nitrogênio líquido, até a obtenção de um pó. Em seguida foram adicionados $1,5 \mathrm{~mL}$ de tampão fosfato de sódio $50 \mathrm{mM}$, $\mathrm{pH}$ 7,0 (peroxidases) ou tampão acetato de sódio $0,1 \mathrm{M}, \mathrm{pH}$ 5,0 (glucanases), contendo fluoreto de fenilmetanosulfonila (1 mM) (Sigma, EUA). A suspensão foi transferida para microtubos de $2 \mathrm{~mL}$, centrifugada a $20.000 \mathrm{~g} / 30 \mathrm{~min}$, a $4^{\circ}$ $\mathrm{C}$, e o sobrenadante foi recolhido (extrato protéico).

A determinação da atividade de peroxidases seguiu a metodologia descrita por Stadnik e Buchenauer (2000), utilizando guaiacol 0,25\% (v/v) (Sigma, EUA) e peróxido de hidrogênio 0,1 M (Merck, Alemanha) como substratos e os resultados foram expressos como unidades de Densidade Óptica a $470 \mathrm{~nm} / \mathrm{mg}$ proteína /min, após a determinação do conteúdo de proteínas totais nas amostras pelo método de Bradford (1976). A atividade de glucanases foi conduzida utilizando laminarina como substrato, conforme descrito por Di Piero \& Pascholati (2004), quantificando-se os açúcares redutores pelo método de Lever (1972), e os resultados foram expressos em $\mu \mathrm{Katal} / \mathrm{mg}$ de proteína, sendo que 1 Katal é definido como a atividade enzimática que cataliza a formação de $1 \mathrm{~mol}$ de equivalente-glicose / segundo.

$\mathrm{O}$ experimento foi realizado utilizando-se o delineamento completamente casualizado. Para a avaliação do número e tamanho de pústulas foram utilizadas duas plantas de um vaso com três plantas como unidade experimental, a planta restante foi utilizada para a retirada de amostras para as observações microscópicas ou atividades de peroxidases e glucanases. Ao todo foram utilizadas oito repetições para as análises do número e diâmetro das pústulas. Para as análises microscópicas e enzimáticas, foram utilizadas quatro repetições. Depois de verificada a homogeneidade das variâncias, os dados foram submetidos à análise de variância (ANOVA) com esquema fatorial $(3 \times 2)$ e ao teste de Tukey a $5 \%$ de probabilidade.

A pulverização do polissacarídeo ulvana não afetou o número de pústulas $/ \mathrm{cm}^{2}$ da ferrugem (dados não mostrados), mas promoveu uma redução média de $23,8 \%$ no diâmetro das mesmas em plantas de feijão (cultivares Brígida, Pérola e Juriti) pulverizadas aos 6 e 3 dias antes da inoculação do patógeno (Tabela 1). Este resultado é semelhante aos obtidos por Fernandes (2007) e Araújo et al. (2008) que observaram, respectivamente, redução do crescimento das lesões de Colletotrichum lindemuthianum em feijoeiro e diminuição da severidade da mancha foliar da Glomerella em plântulas de macieira tratadas preventivamente com ulvana.

A pulverização de ulvana não teve efeito sobre a germinação de U. appendiculatus. Por outro lado, verificouse que a maior porcentagem de germinação de uredósporos sobre a superfície foliar foi encontrada na cv. BR IPA11 Brígida (resistente). A porcentagem de apressórios formados sobre estômatos, embora não significativa, também foi maior nessa cultivar (Tabela 2), sugerindo que 
L.C. Borsato et al.

TABELA 1 - Diâmetro médio das pústulas no primeiro trifólio das cultivares de feijoeiro do grupo carioca pulverizados com ulvana (10 $\mathrm{mg} / \mathrm{mL}$ ) ou água destilada, 15 dias após a inoculação de Uromyces appendiculatus

\begin{tabular}{lccc}
\hline \hline & & Diâmetro das pústulas $(\boldsymbol{\mu m})$ & \\
\cline { 2 - 4 } Cultivares & Testemunha & Ulvana & Média $^{\text {a }}$ \\
\hline BR IPA -11 Brígida & 445,5 & 316,8 & $381,2 \mathrm{~b}$ \\
Pérola & 523,0 & 398,5 & $460,8 \mathrm{a}$ \\
IPR Juriti & 616,3 & 490,8 & $553,6 \mathrm{a}$ \\
Média & 528,3 & $402,1 *$ & \\
\hline
\end{tabular}

*significativo pelo teste $\mathrm{F}(\mathrm{p} \leq 0,05)$.

${ }^{a}$ Médias seguidas pelas mesmas letras não diferem entre si pelo teste Tukey ao nível de $5 \%$ de probabilidade.

TABELA 2 - Porcentagem da germinação de uredósporos e formação de apressórios de Uromyces appendiculatus sobre a superfície foliar de cultivares de feijoeiro do grupo carioca pulverizadas ou não com ulvana, $48 \mathrm{~h}$ após a inoculação

\begin{tabular}{lcccccc}
\hline \hline & \multicolumn{2}{c}{ Germinação de uredósporos \% } & \multicolumn{2}{c}{ Formação de apressórios \% } \\
\cline { 2 - 7 } Cultivares & Testemunha & Ulvana & Média* $^{*}$ & Testemunha & Ulvana & Média $^{\text {ns }}$ \\
\hline BR IPA-11 Brígida & 76,7 & 81,6 & $79,2 \mathrm{a}$ & 39,7 & 34,0 & 36,8 \\
Pérola & 65,2 & 43,7 & $54,4 \mathrm{~b}$ & 21,8 & 24,3 & 23,0 \\
IPR Juriti & 54,6 & 62,6 & $58,7 \mathrm{~b}$ & 33,0 & 24,0 & 28,4 \\
Média & 65,5 & $62,7{ }^{\mathrm{ns}}$ & & 31,5 & $27,4^{\mathrm{ns}}$ & \\
\hline
\end{tabular}

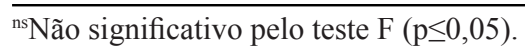

*Médias seguidas pelas mesmas letras não diferem entre si pelo teste Tukey ao nível de 5\% de probabilidade.

o mecanismo de resistência da cv. Brígida atue em fases posteriores à infecção.

As atividades de duas enzimas relacionadas com a defesa foram detectadas em todas as cultivares de feijoeiro estudadas, independente do nível de resistência. A atividade de peroxidases pode produzir radicais livres tóxicos para o patógeno e participar do reforço da parede celular da planta através do envolvimento nas etapas finais da biossíntese de lignina (Stadnik \& Buchenauer, 2000). Observou-se que a atividade de peroxidases 48 horas após a inoculação foi maior na cv. IPR Juriti, caracterizada como suscetível, com um aumento de pelo menos $65 \%$ em relação à atividade na cv. resistente BR IPA - 11 Brígida, independente do tratamento com ulvana (Figura 1). Roldán Serrano et al. (2007) verificaram que as atividades de peroxidases e quitinases em hipocótilos de plântulas de girassol também foram significativamente maiores nas plântulas suscetíveis ao míldio (Plasmopara halstedii). A pulverização de ulvana não afetou significativamente a atividade de peroxidases quando comparada com as amostras pulverizadas com água destilada (Figura 1).

A $\beta$-1,3-glucanase é uma enzima hidrolítica que apresenta ação direta contra o patógeno, degradando sua parede celular e possivelmente atuando como uma barreira química, inibindo a formação do haustório na célula hospedeira (Hu \& Rijkenberg, 1998). A exemplo do ocorrido para as peroxidases, plantas da cv. resistente BR IPA - 11
Brígida apresentaram menor atividade desta enzima que a cv. suscetível IPR Juriti. A pulverização de ulvana causou o aumento da atividade de glucanases somente nas plantas da cv. Pérola (moderadamente suscetível), mas não em Juriti, uma cultivar com maior nível de suscetibilidade (Figura 2). Desse modo, a participação dessa enzima na redução do número de pústulas da ferrugem é questionável. Uma explicação para este resultado contraditório é que não são todas as glucanases que possuem atividade antifúngica (Sela-Buurlage et al., 1993). Rauscher et al. (1999) observaram aumento na expressão de $\beta$-1,3-glucanases e quitinases em plantas de feijão-fava tratadas e não tratadas com os indutores ácido salićlico e ácido 2,6- dicloro isonicotínico, no entanto, a presença dessas enzimas não afetou o desenvolvimento de $U$. fabae.

Em algumas situações, o aumento na atividade enzimática pode ser mais uma conseqüência do metabolismo da planta após a infecção do que propriamente uma resposta conduzindo à defesa (Roldán Serrano et al., 2007). Para a maioria dos fungos causadores de ferrugens, o primeiro haustório é formado entre 24 e 48 horas após a inoculação das plantas (Emeran et al., 2005), enquanto que as análises de peroxidases e glucanases do atual trabalho foram efetuadas 48 horas depois. Pode ser que o genótipo suscetível, não bloqueando a colonização fúngica $\operatorname{logo}$ nas fases iniciais através de mecanismos bioquímicos e estruturais de resistência, passou a produzir uma 
Mecanismos de defesa eliciados por ulvana contra Uromyces appendiculatus...

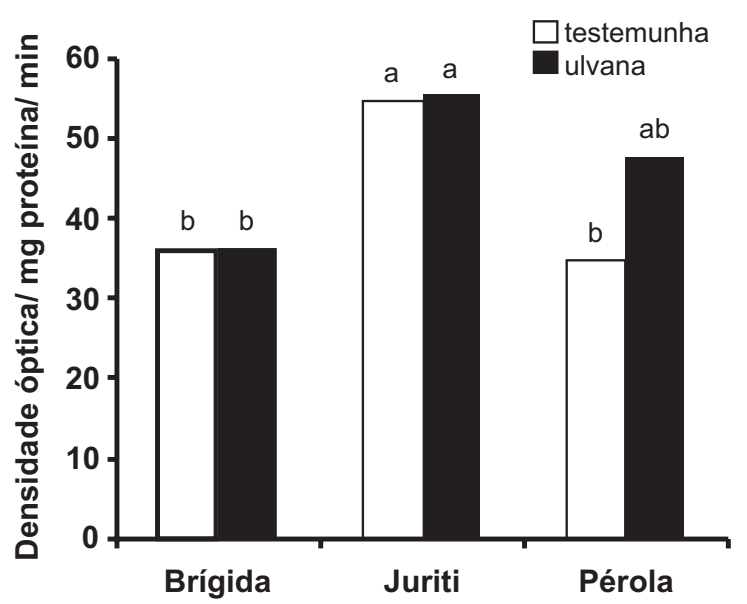

FIGURA 1 - Atividade de peroxidases 48 horas após a inoculação de Uromyces appendiculatus em cultivares de feijoeiro do grupo carioca BR IPA - 11 Brígida, IPR Juriti e Pérola pulverizadas ou não com ulvana.

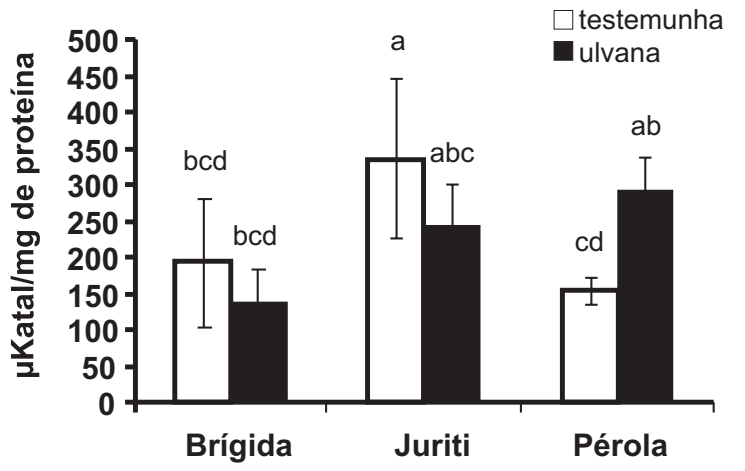

FIGURA 2 - Atividade de glucanases 48 horas após a inoculação de Uromyces appendiculatus em cultivares de feijoeiro do grupo carioca BR IPA - 11 Brígida, IPR Juriti e Pérola pulverizadas ou não com ulvana.

grande quantidade de enzimas de defesa num momento inoportuno, quando a atividade dessas já não poderia mais atuar eficientemente sobre o fungo. Ao contrário, o genótipo resistente, restringindo a colonização fúngica logo nas primeiras etapas, cessou a ativação de repostas de resistência, culminando com uma menor biossíntese de glucanases e peroxidases nas fases posteriores.

Por outro lado, Siegrist et al. (1997) verificaram associação da redução da severidade da ferrugem e a alta produção de glucanases em fluídos intercelulares de folhas de feijoeiro tratados com acibenzolar-S-metil (ASM) e inoculados com $U$. appendiculatus quando comparadas com as plantas não tratadas. Iriti \& Faoro (2003), trabalhando com o mesmo patossitema através de análises histológicas, observaram o acúmulo de peróxido de hidrogênio nos tecidos das folhas entre 12 e 48 horas após o tratamento com ASM, mas sem a ocorrência de reação de hipersensibilidade, evidenciando a alta atividade de peroxidase nas plantas que expressaram resistência, atuando principalmente no reforço da parede celular pela ligação de proteínas e deposição de lignina. Dessa forma, no presente trabalho, não foi possível atribuir isoladamente a um dos mecanismos de defesa estudados um papel de grande significância na resistência de feijoeiro à ferrugem ou na forma de atuação do polissacarídeo ulvana.

\section{AGRADECIMENTOS}

MJS agradece ao Conselho Nacional de Desenvolvimento Científico e Tecnológico - CNPq pela bolsa de produtividade.

\section{REFERÊNCIAS BIBLIOGRÁFICAS}

Araújo L, Stadnik MJ, Borsato LC, Valdebenito-Sanhueza RM (2008) Fosfito de potássio e ulvana no controle da mancha foliar da gala em macieira. Tropical Plant Pathology 33:148-152.

Aziz A, Poinssot B, Daire X, Adrian M., Bézier A, Lambert B, Joubert JM, Alain A (2003) Laminarin elicits defense responses in grapevine and induces protein against Botrytis cinerea and Plasmopara viticola. Molecular Plant-Microbe Interactions 16:1118-1128.

Bradford MM (1976) A rapid and sensitive method for the quantitation of microgram quantities of protein utilizing the principle of protein-dye binding. Analytical Biochemistry 72:248254.

Cluzet S, Torregrosa C, Jacquet, C, Lafite C, Fournier J, Mercier L, Salamagne S, Briand X, Esquerré-Tugayé MT, Dumas B (2004) Gene expression profiling and protection of Medicago truncatula against a fungal infection in response to an elicitor from green algae Ulva spp. Plant Cell and Environment 27:917-928.

Di Piero RM, Pascholati SF (2004) Efeito dos cogumelos Lentinula edodes e Agaricus blazei na interação entre plantas de tomate e Xanthomonas vesicatoria. Summa Phytopathologica 30:57-62.

Emeran AA, Sillero JC, Niks RE, Rubiales D (2005) Infection structures of host-specialized isolates of Uromyces viciae-fabae and of other species of Uromyces infecting leguminous crops. Plant Disease 89:17-22.

Fernandes WS (2007) Respostas de defesa e resistência induzida por ulvana à antracnose (Colletotrichum lindemuthianum) em cultivares de feijoeiro comum (Phaseolus vulgaris L.). Dissertação de Mestrado. Universidade Federal de Santa Catarina. Florianopolis SC.

Hu G, Rijkenberg FHJ (1998) Subcellular localization of $\beta-1,3-$ glucanase in Puccinia recondita f.sp. tritici infected wheat leaves. Planta 204:324-334.

Iriti M, Faoro F (2003) Benzothiadiazole (BTH) induces cell-death dependent resistance in Phaseolus vulgaris against Uromyces appendiculatus. Journal of Phytopathology 151:171-180.

Jesus Junior WC, Vale FXR, Martinez CA, Coelho RR, Costa LC, Hau B, Zambolim L (2001). Effects of angular leaf spot and 


\section{L.C. Borsato et al.}

rust on leaf gas exchange and yield of common bean (Phaseolus vulgaris). Photosynthetica 39:603-606.

Kiraly L, Barna B, Kiraly Z (2007). Plant resistance to pathogen infection: forms and mechanisms of innate and acquired resistance. Journal of Phytopathology 155: 385-396.

Lever MA (1972) New reaction for colorimetric determination of carbohydrates. Analytical Biochemistry 47:273-279.

Mcmillan MS, Schwartz HF, Otto KL (2003) Sexual stage development of Uromyces appendiculatus and its potential use for disease resistance screening of Phaseolus vulgaris. Plant Disease 87:1133-1138.

Paulert R, Talamini V, Cassolato JEF, Duarte MER, Noseda M, Smania Júnior A, Stadnik MJ (2009) Effects of sulfated polysaccharide and alcoholic extracts from green seaweed Ulva fasciata on anthracnose severity and growth of common bean (Phaseolus vulgaris L.). Journal of Plant Diseases and Protection 116:63-270

Rauscher M, Adám AL, Wirtz S, Guggenheim R, Mendgen K, Deising HB (1999) PR-1 protein inhibits the differentiation of rust infection hyphae in leaves of acquired resistant broad bean. The Plant Journal 19:625-633.

Roldán-Serrano A, Luna Del Castillo J, Jorrín Novo JA, Fernández Ocaña A, Gómez Rodriguez MV (2007) Chitinase and peroxidase activities in sunflower hypocotyls: effects of BTH and inoculation with Plasmopara halstedii. Biologia Plantarum 51:149-152.

Sela-Buurlage MB, Ponstein AS, Bres-Vloemans SA, Melchers LS, Elzen P, van den Cornelissen B (1993) Only specific tobacco (Nicotiana tabacum) chitinases and $\beta-1,3$ glucanases exhibit antifungal activity. Plant Physiology 101:857-863.

Siegrist J, Glenewinkel D, Kolle C, Schimidtke M (1997) Chemically induced resistance in green bean against bacterial and fungal pathogens. Journal of Plant Disease and Protection 104:599-610.

Singh SP (2001) Broadening the genetic base of common bean cultivars: A review. Crop Science 41:1659-1675.

Stadnik MJ, Buchenauer H (2000) Inhibition of phenylalanine ammonia-lyase suppresses the resistance induced by benzothiadiazole in wheat to Blumeria graminis f. sp. tritici. Physiological and Molecular Plant Pathology 57:25-34.

TPP 72 - Recebido 3 Fevereiro 2010 - Aceito 29 Outubro 2010 Editor de Seção: Marisa A.S.V. Ferreira 